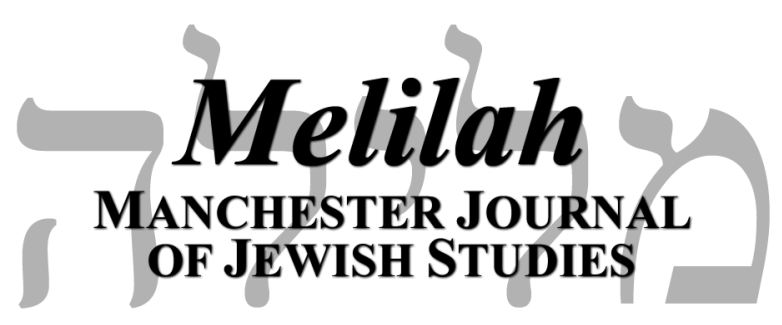

\author{
EDITOR \\ Daniel R. Langton \\ ASSISTANT EDITOR \\ Simon Mayers
}

Title: Kaplan and Wittgenstein: Atheism, Phenomenology and the use of language Author(s): MICHAEL T. MILLER

Source: Melilah: Atheism, Scepticism and Challenges to Monotheism, Vol. 12 (2015), pp. $70-83$

Published by: University of Manchester and Gorgias Press

URL: http://www.melilahjournal.org/p/2015.html

ISBN: 978-1-4632-0622-2

ISSN: 1759-1953

A publication of the Centre for Jewish Studies,

University of Manchester, United Kingdom.

Co-published by

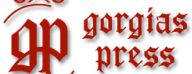




\title{
KAPLAN AND WITTGENSTEIN: ATHEISM, PHENOMENOLOGY AND THE USE OF LANGUAGE
}

\author{
Michael T. Miller*
}

\begin{abstract}
The attempts of Mordecai Kaplan and Ludwig Wittgenstein at reforming Jewish theology and analytic philosophy respectively share some important traits. While Kaplan's scientifically respectable "atheistic" Judaism sought to reinterpret theological principles in line with a modern-day materialist vision of the cosmos, Wittgenstein's reductionist anti-metaphysical philosophy attempted to show that language often leads thought astray by concealing unjustified presuppositions. Both thinkers were involved in a process of cleaning language - of removing terms from common use in order to refine, redefine, and strip away layers of misleading mythology so that they can be returned, purified, to everyday use. This paper will examine their thought side by side in order to demonstrate the similarities between their thought as well as what they can teach us about the role of metaphysics in deconstructing the theism-atheism binary. I will argue that there is a current of immanence which unites their efforts, flattening the world into a phenomenal-experiential plane where religious terminology is still retained as crucial for the exercise of meaningful human life but is understood to relate to the immediate lived experience. As a result of this de-ontologising, religion becomes a matter of ideology rather than objective truth and ethics becomes paramount.
\end{abstract}

\section{Introduction}

This paper will offer a comparison of the philosophical outlooks, particularly with regard to metaphysics and language, of two important twentieth-century thinkers, the legacy of whom has, if anything, grown since their passing. I will suggest that in examining Kaplan and Wittgenstein side by side we find grounds for problematizing the concept of a simplistic atheism-theism binary, something which itself requires a specific metaphysical outlook. But to begin with, we might want to ask why these two would be thought of in the same sentence at all?

Mordecai Kaplan, the founder of Reconstructionism (born in Lithuania, lived most of his life in America, 1881-1983), and analytic philosopher Ludwig Wittgenstein (born in Austria but lived most of his life in England, 1889-1951) lived at roughly the same time and were both attempting to navigate the currents of modernism in the milieu of the early-twentieth century. Both were in some sense Jewish: Kaplan, the son of a rabbi, himself underwent rabbinic training (at the Jewish Theological Seminary) and ordination, although he quickly became dissatisfied with the intellectual outlook of the Orthodox rabbinate and began to devise a new approach to scripture and practice, one which integrated the scientific knowledge and social developments which were a part of his world. Wittgenstein was born into a Christian family, but three of his four grandparents

\footnotetext{
*Visiting Lecturer in Jewish Studies at Liverpool Hope University. Email: michael.miller@nym.hush.com
} 
had been Jewish. While religious matters concerned him deeply, ${ }^{1}$ he had no explicit Jewish influence on his upbringing and his interest in the Bible was focussed on the New Testament. However, his own self-perception was that he was a Hebrew and a part of the Jewish people. ${ }^{2}$ More importantly, both were strictly anti-metaphysical thinkers: throughout his philosophical work, Wittgenstein argued that we are led astray by a literal conception of language, picturing language as something like a trap with all kinds of metaphysical implications ready to skewer us; ${ }^{3}$ and Kaplan desired to reconstruct Jewish religion away from its old metaphysical assumptions towards a new doctrine which was pragmatic and grounded in practise. For both thinkers, their work was part of a philosophy of life, and so, when Wittgenstein claimed that the "meaning of the world," something that lies outside of the factual boundaries of the world, may be given the name "God," 4 this sounds very similar to Kaplan's belief that "God" should be a term that articulates our fundamental goals and values. ${ }^{5}$ For each thinker the word does not point to an object, but is a principle that the human finds above and beyond material facts.

So there is a basic similarity in their projects, despite the fact that neither seems to have been aware of the other's existence. ${ }^{6}$ In this paper I will argue that this similarity goes deeper than mere surface forms, and that there is a rigorous philosophical outlook which unites them, although it is often expressed in different ways. Placing these two thinkers side by side will help to demonstrate their similarity, and it may also help us to understand each one of them better.

Specifically, what I will attempt to show is that there is a crucial phenomenological aspect to both Kaplan and Wittgenstein's thought; they share a fundamental emphasis on subjective human life as the ground from which we must begin thinking, and with regard to which all conclusions should be oriented. ${ }^{7}$ Kaplan and Wittgenstein are not trying to describe an objective reality, but are thinking from within the world of the individual human experience. In fact, I will argue, they see the pursuit of ontology as something of an error. This then leads to the perception (and in Kaplan's case the accusation ${ }^{8}$ ) of them

\footnotetext{
${ }^{1}$ The last two or three decades have witnessed an increasing flow of texts on the religious in Wittgenstein's thought.

${ }^{2}$ On Wittgenstein's heritage and relationship with Judaism, see Ranjit Chatterjee, Wittgenstein and Judaism: A Triumph of Concealment (New York: Peter Lang, 2005).

3 "We are engaged in a struggle with language." Ludwig Wittgenstein, Culture and Value, trans. Peter Winch. (Chicago: University of Chicago Press, 1980), 11.

${ }_{4}$ "The meaning of life, i.e. the meaning of the world, we can call God." Ludwig Wittgenstein, note, 11 June 1916, Notebooks 1914-16, ed. G.H. von Wright and G.E.M. Anscombe (Oxford: Blackwell, 1961), 73.

${ }^{5}$ E.g., "God and life are one and the same." Mordecai M. Kaplan, Questions Jews Ask: Reconstructionist Answers (New York: The Reconstructionist Press, 1956), 102; God means "the power manifest in the spiritual aspirations of Israel as making for human self-fulfilment." Mordecai M. Kaplan, note, 30 August 1929, in Communings of the Spirit: The Journals of Mordecai M. Kaplan Volume I, 1913-1934, ed. Mel Scult (Detroit: Wayne State University Press, 2001), 359. Cf., his remark that many people "are alienated because we do not engage frankly in the task of putting new content into the term God" (Kaplan, journal entry 29 January 1935, quoted in Mel Scult, The Radical American Judaism of Mordecai Kaplan (Bloomington, IN: Indiana University Press: 2013), 113), and Wittgenstein's remark that "Sometimes an expression has to be withdrawn from usage and sent for cleaning, - then it can be put back into circulation." Wittgenstein, Culture and Value, 39.

${ }^{6}$ There is no recorded mention by either of the other one. Kaplan refers several times to Wittgenstein's early mentor at Cambridge, Bertrand Russell - though not in terms entirely approving; e.g. in Mordecai M. Kaplan, The Meaning of God in Modern Jewish Religion (Detroit: Wayne State University Press, 1994), 27.

${ }^{7}$ As Martin Stokhof writes, "Our experience as humans, both of the world and of ourselves, is the starting and end point of almost all of Wittgenstein's investigations." Martin Stokhof, World and Life as One. Ethics and Ontology in Wittgenstein's Early Thought (Palo Alto: Stanford University Press, 2002), 2.

${ }_{8}$ Certainly for many years Wittgenstein was unquestioningly considered an atheist; within the community of scholars interested in his work outside of purely analytic matters there is now more nuance. While this paper is dedicated to problematizing the idea and meaning of atheism, it is worth noting that several commentators have
} 
embracing atheism, since they are dogmatically rejecting any claim of the existence of God as such; but for both thinkers, religious truth and divinity still do happen as realities of human life, as events within the human world, and as such are important aspects of life which should be taken into account in order to live correctly - which is to say healthily, or "ethically" in the broad sense.

I will begin with a short discussion of how religion functions in their thought, as a fundamentally anthropocentric activity; this will lay the ground for a deeper investigation of the meaning of this anthropocentrism within their philosophies, and how this informs their metaphysics, such that both have often been considered to be atheists - I term this their immanence - and finally, the implications of this immanent metaphysics for theology (or atheology if one prefers) will be unpacked.

\section{The Anthropocentric Nature of Religion}

For the pragmatist Kaplan, the essence of religion is not a body of dogma but a practice it is a doing. It is only in the living and performing of a religion that one can discover its meaning, and this meaning is found through the concrete effects which the practitioner experiences. In the practice of religion, we experience that which we call God, and this experience is more meaningful than any theological theory. So, "God must not merely be held as an idea; He must be felt as a presence if we want not only to know about God but to know God." 9 The attempt to find theoretical knowledge of God is like a category error: the important part of religion is how it affects our living, and makes us feel valued and connected to society and the cosmos. For Kaplan it is the human end, the struggle for identity and salvation as they are experienced in our lives, which is of ultimate value, rather than the abstract physical process which leads to it. While Kaplan identifies the term "God" with those structures in the cosmos which make it possible for human beings to live meaningful lives, to seek and attain salvation, it is not the processes themselves which are important but how human beings utilise them. This is to say that the mechanical physical systems which scientifically undergird the events in human life are irrelevant to the actual living of that life; they offer us nothing. Explanations are, in this sense, useless even when correct.

For Wittgenstein too, ${ }^{10}$ religious rites have to be understood in terms of their practice. In his Remarks on Frazer's Golden Bough, ${ }^{11}$ he criticises Frazer for positing historical explanations, or even pseudo-scientific theories, behind performances; rather for him, it is the human experience of doing them which explains their existence; it is the effect they have on their participants. While the subject of Frazer's text is primitive religion, for

\footnotetext{
explicitly rejected any such claim in Wittgenstein's regard. In this case the (misplaced) accusation is rather that he was a theist. See for example Cyril Barrett, Wittgenstein on Ethics and Religious Belief (Oxford: Blackwell, 1991).

${ }^{9}$ Kaplan, Meaning of God, 244.

10 "Our experience as humans, both of the world and of ourselves, is the starting and end point of almost all of Wittgenstein's investigations.” Stokhof, World and Life as One, 2.

${ }^{11}$ Ludwig Wittgenstein, Remarks on Frazer's Golden Bough, trans. A.C. Miles and R. Rhees (Herefordshire: Brynmill, 1979). This text, like many of Wittgenstein's posthumously published works, is a collection of notes, here taken from his annotated copy of J. G. Frazer's The Golden Bough. While trying to ascertain a mature philosophy from scribbled musings and marginal notes is not recommended, these fragments do fit very well with the implications of his more developed and polished output.
} 
Wittgenstein the implications are undoubtedly applicable to all expressions of religious thought and practice, and so drawing the parallel with more familiar thinkers, he asks, "Was Augustine mistaken, when he called on God on every page of the Confessions? [...] if he was not then the Buddhist holyman, or some other surely was. But none of them was making a mistake except where he was putting forward a theory." ${ }^{12}$ Modern religion should likewise be understood not as a doctrine about the world, but as an ethical approach to it, and that is to say it is a matter of living rather than thinking. If it is not a theory about the world which provokes religious behaviour, what might it be? The answer is in the experience of the rites themselves: "What strikes us [in rituals] as terrible, impressive, horrible, tragic, etc., [...] that is what gave birth to them." 13

It is important to remember that, whenever we want to investigate how things are for humans, the world in itself as an object of investigation is never enough - and this is because human concepts are formed at the interface of the objective world and consciousness. Consciousness as such will always manipulate and translate the raw data, in terms both integral to consciousness, and those based upon previous experience and culture; which is to say that consciousness is primed or rewired by experience. And so as Alan Keightley puts it,

\footnotetext{
"Our particular rules of grammar reflect the style of human life and the 'facts of nature' as we find them. The essential point is that the facts alone do not account for the concepts we have. Indeed, what we have come to regard as 'the facts' is dependent upon the techniques, ways of speaking, etc., which have made our life what it is." ${ }^{14}$
}

While the concept of measurement or length is not arbitrary, that $12 "=1$ ' is, as it is determined by our culture and our intellectual history (which themselves present such things to us as facts). The arbitrariness of grammar must always be tempered by knowing that we do not and cannot choose what structures we find imposed upon us by this combination of world, human nature, and experience. Thus "A whole mythology is deposited in our language." 15

While this mythology can tell us little about an objective reality, it can tell us much about our culture, and how our intellectual world is constructed. Wittgenstein describes certain presumptions, things like "the earth exists," which we take as sureties of thought; and according to Wittgenstein, "Perhaps it was once disputed. But perhaps, for unthinkable ages, it has belonged to the scaffolding of our thoughts. (Every human being has parents.)" 16 These presumptions are not unquestionable, but help to form the basic terms in which we think. We do not even notice them being there, they are not consciously held at every stage but they help form the rules we think by.

\footnotetext{
12 Wittgenstein, Remarks on Frazer, 1-3

13 Wittgenstein, Remarks on Frazer, 3

${ }_{14}$ Alan Keightley, Wittgenstein, Grammar and God (London: Epworth Press, 1976), 45. Cf. Ludwig Wittgenstein, Philosophical Investigations, trans. G.E.M. Anscombe, new edition (Oxford: Blackwell, 1968), 230.

${ }^{15}$ Wittgenstein, Remarks on Frazer, 35.

${ }^{16}$ Ludwig Wittgenstein, On Certainty, ed. G.E.M.Anscombe and G.H.von Wright, trans. Denis Paul and G.E.M. Anscombe (Oxford: Basil Blackwell, 1975), 211.
} 


\section{Immanence in Kaplan and Wittgenstein}

Wittgenstein's idea that the meaning of religious rites is present immediately within the performance of the rites themselves is part of the same agenda which holds the meaning of language to be in its use. He never seeks to explain religious belief, because his philosophy necessitates that once the facts are laid out in perspicuous arrangement, their order and meaning is immediately apparent; there is no concealed explanatory layer to reality which we have to discover through complex analysis. ${ }^{17}$ In the Tractatus, language correctly-used can perfectly describe the world, and if we can describe accurately, then we have done all the explaining we can do: the structure is open to see, and is shown in a way that other words can never do. This is basically to say that it is not possible to rephrase propositions in a clearer way than the logically correct form - this itself perspicuously demonstrates meaning because of the isomorphism between words and objects. In other words, meaning is immanent in the facts.

While the linguistic theory of the Investigations is more complex, such that language use must be understood as part of a language-game, ${ }^{18}$ we still find the same basic argument in Wittgenstein's contention that a word's meaning is determined by how it is used; that is to say, is found in its grammar rather than in some ghostly aura hanging over it. So, when examining the meaning of the word "imagination," "One ought to ask, not what images are or what happens when one imagines anything, but how the word 'imagination' is used." ${ }^{19}$ In such cases, we are getting as close as is possible to the true nature of the word, because "Essence is expressed by grammar" ${ }^{20}$ and "grammar tells what kind of object

\footnotetext{
${ }^{17}$ Because, correctly practised, "philosophy simply puts everything before us, and neither explains nor deduces anything." Wittgenstein, Investigations, §126.

${ }_{18}$ The later Wittgenstein's emphasis on language games and Forms of Life is part of a concern with multiplicity, an outright rejection of his earlier assumption that there is a single thing, object-nature, which determines the world and experience. Rather, logic is a particular and is embedded in various forms in different language games, each of which sets their own rules for its use. It is language which masks quite how different the internal logics are: "We remain unconscious of the prodigious diversity of all the everyday language-games because the clothing of our language makes everything alike" (Wittgenstein, Investigations, 224). While commentators such as Tim Labron, Wittgenstein and Theology (London: T\&T Clark, 2009) are correct that Wittgenstein's later work marks a significant shift towards a less firm and more multifaceted conception of language, there is no change in the strict immanence with which he viewed meaning: the same refusal of a significant intellectual strata, or a set of rules separate from things as they are, is present already in the Tractatus. In fact the shift is from Wittgenstein's belief in subsistent objects as the substance of the world (Wittgenstein, Tractatus, §2.021), and which are therefore defined intersubjectively regardless of specific community, to the belief in multiple grammatical structures which emerge within specific contexts and determine the usage of words independently of each other. In each specific language-game, however, words function in exactly the same way as do objects in the form of the world in the Tractatus; while in the latter the possibilities of objects' placement into states of affairs is determined by the objects' own properties, in the former the object-words' natures are determined by their location in states of affairs (language-games); and so just as in terms of beliefs, "What stands fast does so, not because it is intrinsically obvious or convincing; it is rather held fast by what lies around it" (Wittgenstein, On Certainty, 144), so objects/words and the system they constitutively exist in are fully determinative of each other. All this is to say, that all we can know about the facts and their determination is present perspicuously within the facts and the elements that constitute them. Cf, "If I know an object I also know all its possible occurrences in states of affairs" (Wittgenstein, Tractatus, §2.0123); "Every one of these possibilities must be part of the nature of the object." (ibid., §2.0121); "The possibility of its occurring in states of affairs is the form of an object." (Wittgenstein, Tractatus, \$2.0141) and "Essence is expressed by grammar" (Wittgenstein, Investigations, $\S 371)$, "grammar tells what kind of object anything is" (ibid., §373), "the place of a word in grammar is its meaning." Wittgenstein, Philosophical Grammar, ed. Rush Rhees, trans. Anthony Kenny (Berkley: University of California Press, 2005), 59.

${ }^{19}$ Wittgenstein, Investigations, $\$ 370$. He adds, "But that does not mean that I want to talk only about the word."

20 Ibid., $\$ 371$.
} 
anything is." ${ }^{21}$ There is nothing outside of language which determines meaning; meaning does not match up with any "objective" qualities - or even objects - rather all it does is delineate how our concepts work in practice. ${ }^{22}$ Grammar itself is never justified and cannot be explained with reference to external realities, and so in some sense is arbitrary; but really it merely gives expression to some principles of our experience, of our reason and judgements. All we can do with respect to the "rules" of grammar is describe how grammar works, what role particular kinds of words play. A further corollary could be found in the systematisation of another branch of human involvement with the world: is it correct to claim that there are only three primary colours? It would be entirely meaningless to talk about a sense-independent justification for the categorisation of colours, because for one thing colours occur only via sense, and for another any method of breaking up the frequency spectrum is completely arbitrary. Even though there are indeed physical structures which cause the experience of colour and different variations in colour, their categorisation is entirely within the realm of human social discourse. Here, phenomena and language are totally intertwined.

If the facts themselves are the full expression of meaning, if meaning occurs completely within the event of the facts (whether these are linguistic or material events), then we can do nothing except clearly state things as they are and examine this arrangement of elements for their sense. There is no deeper strata which controls the process of signification, nor a concealed key which we must find and use to open up the meaning; everything is discoverable from the surface form; there is nothing but the surface form. Just as to say that "the work of art does not convey something else, just itself," ${ }^{23}$ whereby there is no intention behind the work for which it was created, rather the work itself is the only satisfactory explanation of its meaning. Also "[a] picture cannot [...] depict its pictorial form; it displays it," ${ }^{24}$ meaning that the form or essence of a picture does not exist behind it, represented by the picture, but rather exists in the picture, being displayed as the picture itself. Art is not symbolic, it does not point outside itself. If there is a meaning, then the work of art or picture must be the best way of expressing that meaning; we cannot find it outside of the work, or describe it more accurately in any other way. ${ }^{25}$ And in the same way, Kaplan argues that what is of value in the practice of religion is not something which we can get to by going around religious practice; we get to it in the most effective way through religion.

A similar stripping away of metaphysics is exhibited by Kaplan, who identified God with the processes in the world which provide the possibility of individual human salvation, of identity and of living a meaningful life. Like Wittgenstein, he argued that we can be trapped by a particular usage of the word "God" which is no longer sensible to us. So,

\footnotetext{
${ }^{21}$ Ibid., §373. Pointedly, he adds to this sentence the bracketed equation: “(Theology as grammar)."

22 Alan Keightley, Wittgenstein, Grammar and God (London: Epworth Press, 1976) writes that, "When Wittgenstein says that 'grammar tells what kind of object anything is', he is not concerned to relate the physical features of an object. The grammar of 'chair' establishes the concept of a chair in our whole system of concepts" (43). What we are investigating here is the subsistent object-names which are the substance of the phenomenal world we inhabit; the substances of thought. "Like everything metaphysical the harmony between thought and reality is to be found in the grammar of the language" Wittgenstein, Philosophical Grammar, 162.

${ }^{23}$ Wittgenstein, Culture and Value, 58.

${ }^{24}$ Wittgenstein, Tractatus, $\$ 2.172$.

25 "An explanation is internal to a particular language game. There is no explanation that rises above our languagegames, and explains them." Norman Malcolm, Wittgenstein: A Religious Point of View? ed. Peter Winch (New York: Cornell University Press, 1995), 24.
} 
rather than platitudes like "God is love," Kaplan suggested we rethink theology in terms of "love is God," 26 removing the anthropomorphic subject and focussing instead on predicates. Kaplan himself saw this in Maimonidean terms of trying to not discuss the unfathomable essence of God - a tactic which might then lead us to a quite base materialism - but instead focussing on what we do know: the attributes. God, then, is known as immanent in the world, and is directly experienced in human life. In fact Kaplan thinks of the teaching he is critiquing as a form of idolatry, which he defines as a most human tendency to transform simple ephemeral processes into permanent objective things. It is objectification, or as Kaplan's neologism has it, to "thingify"; a practice peculiarly continued by theologians, as "Only theologians have a tendency to bring into the field of mature thought the tendency of the immature mind to reify, or thingify, processes, relations and events as though they were identifiable entities." ${ }^{27}$

At another point Wittgenstein argues that a ritual action like burning an effigy is similar in nature to kissing a loved one's picture; it is the very performance which explains itself. There is no theory behind it, no intellectual aspect beyond the desire and the concomitant feeling of satisfaction. And,

"This is obviously not based on a belief that it will have a definite effect on the object which the picture represents. It aims at some satisfaction and it achieves it. Or rather, it does not aim at anything; we act in this way and then feel satisfied." 28

Kaplan likewise explicates the practice of Jewish festivals in terms of their direct relevance to contemporary religious life: not their past but their effect is their justification. ${ }^{29}$ The ritual and the effect it has on the participants explain its use perfectly. Kaplan expresses the subjective value of religious experience, claiming that "no religious experience is genuine without elements of awe and mystery, provided they do not lead to occultism and supernaturalism," and that the experience should necessarily confound our rationality such that we do not look beyond it for explanation: "No religious experience is possible without an overwhelming awareness of reality as baffling man's power of comprehension." 30 However, Mel Scult concludes that while "Kaplan confronts the mystery as does any sensitive religious thinker, [still] he never moves beyond the mystery, never posits a supernatural self, never posits a meaning beyond the mystery as Heschel does." ${ }^{31}$ Kaplan,

\footnotetext{
26 "If instead of affirming that God is love, spirit, etc. there were a new religion to proclaim that love is God, that spirit, courage, devotion, etc. are all but aspects of the love that is God, we might have a religion that is in accord with reality as man now knows it to be. Only when the term God will come to have an adjectival force instead of being a substantive, will it exercise a wholesome effect upon human life.” Kaplan, journal entry 3 September 1922, quoted in Scult, Radical American Judaism, 135.

27 "Soterics," unpublished manuscript, Reconstructionist Rabbinical College Archives, 41, quoted in Mel Scult, The Radical American Judaism of Mordecai Kaplan (Bloomington, IN: Indiana University Press: 2013), 119.

${ }^{28}$ Wittgenstein, Remarks on Frazer, 4. Clack argues that "the language of religion (the articulation of religious beliefs) is an extension of certain primitive reactions, say a natural expression of wonder or of fear. Note, however, that the religious belief is not equivalent to that expression of wonder (the expressivist view)." Brian R. Clack, Wittgenstein, Frazer and Religion (Basingstoke: Macmillan Press Ltd., 1999), 85. Therefore, "it is inconceivable that an elaborately worked-out doctrinal system could come into existence without the initial, affective, primitive reactions he emphasizes" (86).

${ }_{29}$ "[W]e may define [religious ceremony] as the conventional sign language of social relations. The main purpose of ceremonial is to give effective, dramatic and abbreviated expression to the various emotions that center about social relations such as deference, regard, fellowship." (Kaplan, note, 26 February 1914, Communings, 68)

${ }^{30}$ Mordecai M. Kaplan, The Future of the American Jew (New York: Macmillan, 1948), 198.

${ }^{31}$ Scult, The Radical American Judaism, 131.
} 
like Wittgenstein, remains at the crucial phenomenal intersection. For them both, it is the experience which is most important, not any speculation as to its effective cause or spiritual relevance.

And so it seems that religion is not a metaphorical description of some truth, but a prerational, and therefore pre-linguistic, activity. The religious then cannot be adequately formulated or expressed in any way: it cannot be said, it can only be shown by its use. ${ }^{32}$ That it does not describe facts about the world means that it also cannot be a metaphor for facts about the world. To attempt to explain religious behaviour by reference to states-ofaffairs (including mental beliefs) is fundamentally flawed. The reason religious rites are practised is not some event thousands of years ago which they commemorate, but it is apparent in the very practicing of the rites.

All this is part of the anti-depth project which is at the root of both their philosophies. Language does not express thoughts which exist regardless of it; and religion is not a theoretical approach to the world, expressing something which exists regardless of humanity. ${ }^{33}$ Reality rather is a flat plane, metaphysically immediate and with no concealed aspect either above or below it; the truth and the meaning of reality are here present within our very experience of them. ${ }^{34}$

\section{The Transcendence that Shines through Immanence}

In the previous sections I argued that Wittgenstein and Kaplan hold the meaning of reality, where reality is the experiential plane we exist in, to be entirely immanent, explained in and by itself. However, this is not the whole story, because while reality must be understood immanently there is a process which happens through this understanding, suggestive of another aspect; prompting the possibility that the immanent universe can itself express something greater than what merely is.

Wittgenstein was firm in asserting that there is no such thing as the self; but all this means is that the word "I" does not refer to an object in the world.

"The I enters into philosophy by the fact that 'the world is my world'. The philosophical I is not man, not the human body, or the human soul with which psychology is concerned [i.e. the composite soul], but the metaphysical subject, the limit - not a part of the world." ${ }_{35}$

\footnotetext{
${ }_{32}$ "[A] simile must be a simile of something. And if I can describe a fact by means of a simile I must also be able to drop the simile and describe the facts without it." Ludwig Wittgenstein, "A Lecture on Ethics (1930)" Philosophical Review 74 (1965): 3-12 (10). Brian Clack argues that "the question is not one of the discourse of religion being either descriptive or non-descriptive, but of what one calls 'description' in the religious context." (Clack, Wittgenstein, Frazer and Religion, 49) Just as 'truth' may mean one thing in one context and something entirely different in another, meaning that we cannot construct a single general theory of how propositions can mean what they mean, so we cannot argue that any proposition must fit a single method of description.

${ }^{33}$ So religious action is not a theoretical approach to the world. Religion does not express existing mind-states or beliefs about reality, but if anything, is the realisation of mind-states.

${ }^{34}$ In arguing this way, Kaplan and Wittgenstein are refuting the kind of dualism which envisions the mind as an isolated ghost within the shell of the body, slowly learning how to communicate across the spatial and epistemic gulf that bodies create. Instead, for these two thinkers, our mind or spirit happens through our bodies and our words; we are diaphanous, transparent to others by our actions except when we deliberately attempt to conceal ourselves. In this case the self is realised via action and we are the sum of our behaviours. It is our public behaviour and interaction which constitutes us; not some evasive gaseous thing lurking inside us.

${ }_{35}$ Wittgenstein, Tractatus, $\$ 5.641$
} 
And so, "The thinking, representing, subject does not exist." ${ }^{6}$ There is no bearer of experiences and qualities. There is no substance in which they inhere. ${ }^{37}$ What we call the substance is just the metaphysical unity of these things, it is nothing but their cohesion, their correlation together into a patterned or structured relation; as a "state of affairs." 38 And this relation is never physically real, always teetering on the brink of destruction merely by the reordering of its constitutive elements (for example, in death).

The same conclusions which Wittgenstein reaches regarding self-identity are reached by Kaplan for Divine identity. He writes that, "to me, God [is] not a being, but Reality viewed as an ordered universe [...] God [is] as much more than an idea as the ego is more than an idea representing the sum of psychic forces in the individual." ${ }^{39}$ Relating this to the already-mentioned conception of predicate-theology, he (much later) wrote, "there is no independent entity or substance called fire. The predicate 'burns' names the process which takes place when we see fire. Likewise when we say God loves, forgives, acts justly, we should understand it to mean that the process of loving, forgiving, and acting justly are divine." 40 While Wittgenstein talks of the humiliation of appearing as an empty tube inflated by a soul, ${ }^{41}$ Kaplan emphasises the divine not as a being which communicates to us through life, but as a process which is realised in the world and in our own actions. Furthermore, the tendency to reify the Divine is precisely what leads us away from its reality as a process, reducing it to an objectified parody: "I regard the notion of being or of substance as due to an intrinsic limitation of the human mind, in that it has to freeze a

${ }^{36}$ Ibid., $\$ 5.631$
${ }_{37}$ "If you talk about essence - you are merely noting a convention.” Ludwig Wittgenstein, Remarks on the Foundations of Mathematics, ed. G.H. von Wright, R. Rhees and G.E.M. Anscombe (Oxford: Basil Blackwell, 1956), 23; cf. Investigations, §92, §371, passim., and Ludwig Wittgenstein, Zettel, ed. G.E.M. Anscombe and G.H. von Wright, trans. G.E.M. Anscombe (Oxford: Basil Blackwell, 1967) §444).

s8 "[A] composite soul would not be a soul anymore." (Wittgenstein, Tractatus, §5.5421) There is no worldly "subject" thing; there is nothing but the elements which constitute the subject. The unity of these is outside the world (it is metaphysical). Stokhof writes, "a subject does not consist of a separate entity over and above the gamut of thoughts, emotions, perceptions, and so forth that it contains" (Stokhof, World and Life as One, 193) and relates this to set theory, that "The relation between a set and its elements in set theory may provide a partial model." (Ibid., 293 , note 11) This is according to the interpretation of the early Wittgenstein as adapting Schopenhauer's will, with a logical structure replacing the epistemological representation. It is important to remember that will does not alter the facts of the world. Will is the attitude of the subject and is an ethical component, but not the instigator of actions (and therefore not a dictator of facts in the world). It is ethical in its relation to what we wish to bring about, we can talk of a pure or corrupt will. It is not ethics in the usual sense of specific actions, but rather our ethical intention in the kind of world we wish to see, and how we connect facts into a whole. This absolute criterion integrates specific actions and events into a larger whole; this integration is ineffable. Any describability implies a connection with contingency, which is all that language can tackle; but the ethical must be concerned with the absolute.

Ergo, to be happy, or live a happy life, is to be in harmony with the world (and the will which transcends it, "upon which I depend"); regardless of the particular manifestation of states of affairs, which are accidental and unaffected by my will anyway; one must accept the world as it is. The human is impotent, cannot impose their will upon the world (and this is certainly a part of Wittgenstein's philosophy which is based on his own experience; in his notebooks he once remarked "I cannot steer the happenings of the world according to my will: am entirely powerless. I can only make myself independent of the world - and thus, in a certain sense, master it - only in so far as I renounce any influence over its happenings." (Wittgenstein, note, 11 June 1916, Notebooks, 73). Although we do not know what he was referring to here, it seems as if he felt it keenly enough to integrate and address it in his philosophy).

Thus, "The facts are all just part of the problem, not of the solution." (Wittgenstein, Tractatus, §6.4321). The solution must be outside, must transcend contingency. The transcendence of ethics is related to the inability to express ethics meaningfully in language (see Wittgenstein, Lecture on Ethics, 15).

${ }^{39}$ Kaplan, note, 13 October 1922, Communings, 169.

40 Kaplan, journal entry 6 November 1952 (quoted in Scult, Radical American Judaism, 135).

${ }^{41}$ Wittgenstein, Culture and Value, 11. 
segment of an ongoing process or becoming in order to think about it." This freezing is done through the use of nouns or substantives; "These substantives lead the mind to reify the segments, when they are objects and to personify them when they are mental constructs. Among the mental constructs are the notions of the human person, or soul and God." ${ }^{2}$ Kaplan's God is no longer a metaphysical proposition separate from real life, performing miracles to gain our attention, but is part of the machinery of reality which correctly has its final expression in human consciousness. He argues that any modern "disconnectedness" from religious rites is because we make an error in expectation: "in past ages $[\ldots]$ this particular complaint that the individual could not experience God in the worship of the synagogue was unheard of." ${ }_{33}$ It is a misunderstanding of both religions' function and its prior integration into everyday life. Just as for Wittgenstein, we know someone is in pain when we see them cradling a limb and whimpering, ${ }^{44}$ for Kaplan we fully know God in the living of a religious life. Wittgenstein is similarly scathing about the problem of 'other minds': "Do I believe in a soul in someone else, when I look into his eyes with astonishment and delight?" 45 To posit such philosophical questions is to deliberately lose touch with the immediacy with which truth is present to us in life. Like the Wittgensteinian I, the Kaplanian God is completely integrated into the world, not concealed from the physical but revealed by it; as it. ${ }^{46}$

Kaplan claims that the important distinction is not between the atheist and the theist, but between those who perceive meaning and order in the world, and those who do not. Wittgenstein believes also that if there is a difference between the world of the believer and that of the atheist, it is mostly in how each connects the same brute facts. In his notebooks he mused that if anything could convince one to believe in God, it is an upbringing which indoctrinates one to sense a tendency in life toward order. ${ }^{47}$

If language (religious or not) does not describe facts about the world but demonstrates the framework of our understanding, then metaphysical statements, which might be mistakenly taken as describing non-material states of affairs (whatever that might mean), are not actually "factual" at all. They define how we interpret. In the famous duck-rabbit drawing, ${ }^{48}$ no facts about the picture change when our perception shifts from one to the other interpretation. Yet in a holistic sense, what we see is completely different. Because the elements have been given a new context (the shape of a rabbit, or of a duck), their relationship to one another, and the subject's relationship to the whole, has become entirely different. And it is the same with religious language: For both Wittgenstein and Kaplan, to place a religious interpretation onto life makes no change or addition to the elements which constitute reality; it does not posit the existence of some supernatural being. Rather, it rearranges the elements of life in such a way that a new meaning emerges, and a

\footnotetext{
${ }_{42}$ Kaplan, journal entry 2 April 1954 , quoted in Scult, Radical American Judaism, 137.

${ }^{43}$ Kaplan, Meaning of God, 263-4.

${ }_{44}$ Wittgenstein, Investigations, §244-250.

${ }^{45}$ Ludwig Wittgenstein, Remarks on the Philosophy of Psychology, trans. G.E.M. Anscombe (Chicago: University of Chicago Press, 1980), 268.

${ }^{46}$ So just as "the place of a word in grammar is its meaning." (Wittgenstein, Philosophical Grammar, 59) for Wittgenstein, so the place of a human in the world determines their life with meaning; we cannot abstract (to do so is a metaphysical error).

47 "Convincing someone of God's existence is something you might do by means of a certain upbringing, shaping his life in such and such a way. Life can educate you to 'believing in God."' Wittgenstein, Culture and Value, 86.

${ }^{48}$ Wittgenstein, Investigations, 194.

$$
\text { ?? }
$$
}


new kind of relationship is possible. It localises the believer within a context of universal direction, whereby 'salvation' is possible. However,

"This should not be interpreted as implying that the belief in God is purely subjective, a figment of the imagination rather than an interpretation of reality. One might as well say that, since the awareness of colour is a subjective experience, it is entirely a creation of the eye, and that no objective reality is responsible for the eye experiencing colour." 49

This is to say that just because it is an interpretation, it does not make it subservient to any other interpretation. In a sense this is the same argument as was famously made by Husserl, ${ }^{50}$ that looking behind appearances and trying to remove the subjective human element from our interpretations is in fact smuggling ever more human speculation into the thought - experience is direct, but positing a reality behind the experience, one devoid of interpretation, is necessarily a speculative endeavour.

On the other hand, to suppose that there is no reality behind the perception, risks another kind of intellectual reductionism. Kaplan insists that there is something real in the world which our God-idea represents and is caused by, even if that something is not formally identical with the idea. ${ }^{51}$ There is after all something objective in the structure of the cosmos to which the aspirations of humanity, our wish for salvation and fulfilment, are related - in other words the possibility of these is part of the structure of reality - which means that the divine, when associated with these, is still something transcendent of those impulses in humanity themselves. The possibility would be meaningless without humans to enact that possibility, so it is only valid in relation to us, and yet it transcends us and exists above and beyond us, regardless of what we do with it (and in fact even whether we exist or not) - that structure is in place in the world out there, and was before we existed and were able to take advantage of it, although it only becomes useful once we are able to use it; in conjunction with us. "The basic spiritual need of our day is to learn to conceive God as manifesting himself both in human nature and in the cosmos of which we are a part, that is, as immanent and transcendent." ${ }_{52}$ For Kaplan this is precisely the unity of all the elements of the universe in which we should have faith, the wholeness; "the very conception of objective reality as cosmos or order, or as a universe in which there obtains absolute uniformity of natural law and complete interaction of all its parts is what we should mean by transcendent and cosmic support." 53 The "transcendent correlative to man's will to salvation" that Kaplan experiences "with the same immediacy as I do my own

\footnotetext{
${ }^{49}$ Kaplan, Meaning of God, 306. Cf. the work of evolutionary biologists establishing that colour in plants evolved alongside the evolution of sight in animals - its raison d'etre being to attract or communicate something to animals, in the hope of manipulating their behaviour in favour of, e.g., consuming fruit and distributing seeds. See, e.g., Mary F. Willson and Christopher J. Whelan, "The Evolution of Fruit Color in Fleshy-Fruited Plants," The American Naturalist 136.6 (1990): 790-809. Kaplan was of course no stranger to evolutionary theory, as discussed in Daniel R. Langton, "Jewish Religious Thought, the Holocaust, and Darwinism: A Comparison of Hans Jonas and Mordecai Kaplan," Aleph 13.2 (2013): 311-348.

${ }_{50}$ Edmund Husserl, Ideas: General Introduction to Pure Phenomenology, trans. W. R. Boyce Gibson (London: George Allen \& Unwin Ltd, 1931).

${ }_{51}$ "We must be careful not to reduce God to the ethical or the communal." "Soterics," 241, quoted in Scult, Radical American Judaism, 138.

${ }^{52}$ Kaplan, journal entry 23 November 1955 , quoted in Scult, Radical American Judaism, 144.

${ }^{53}$ Ibid.
} 
self." ${ }_{54}$ But in the continuation of this passage, Kaplan seems to admit that the divinity of the whole is as illusory as the self is; a necessary fiction which we pursue for pragmatic benefits. 55

If belief in God does not add anything to the world but is just a way of ordering the existing information, what kind of statement does this make it? It describes the metaphysical, trans-factual; it describes the context of reality taken as a whole and talks over, rather than of, the physical. ${ }^{56}$ And this, for both Wittgenstein and Kaplan, is the result of the anti-reductionist tendency which flows through their thought. Which is to say, the reality of human experience should not be reduced to anything else; it is not mere representation of another historical or spiritual reality. But there is something more than this, because both still believe strongly in a form of transcendence. Kaplan writes, "The moment God is merely identified with the world and conceived as being immanent but not transcendent, His Divinity is denied and He is dissolved into the world. This is the atheism and pantheism which religion so vigorously contends against." ${ }_{57}$

This is to say that there is something objective in terms of the processes in the cosmos which correlates with what we think of as God, while God as an object does not exist in the world. ${ }^{8}$ And yet, in being identified with the cosmos, "God" is still in some sense transcendent of it; the divine is not reducible to matter, but still must depend on human beings in order to realise it by effecting that potential in themselves. The connection of the "dots" as divinity is possible, and this possibility is expressed through human subjectivity; something which then generates the metaphysical, and this is the ability to create a new unity from diverse elements, in the form of a meaningful pattern. So, while there is no physically existing entity "God" in the objective cosmos (just as there is no physically real I, only the processes that we conceive as constituting selves), human beings through their conscious action can identify something we call divine through the structure we perceive. ${ }^{59}$

\footnotetext{
${ }^{54}$ Kaplan, journal entry 19 March 1943 , quoted in Scult, Radical American Judaism, 145.

${ }_{55}$ "Intellectually I cannot posit the existence of a self, for the little I know of psychology tells me that the self is an illusion. Yet if I were to deny the reality of the existence of self as a center of initiative I would cut the ground from under the element of responsibility, without which human life is inconceivable. The same holds true of otherhood with its element of loyalty and of godhood with its element of piety." Kaplan, journal entry, 19 March 1943, quoted in Scult, Radical American Judaism, 110.

${ }_{56}$ The metaphysical is in one sense outside and in one sense ever-present within (because there is no outside; it is rather in the ordering of the facts, or we might say it subsists as the relationship between the objects. Wittgenstein was very clear that there is nothing but the facts: even logical operators do not exist, but are an expression of the relation in which objects are located.)

${ }^{57}$ Kaplan, note, 30 March 1913, Communings, 62.

${ }_{58}$ "That factor [self-consciousness] gives to man the consciousness of his own unity as a person. Through the unity of his person he becomes intuitively aware of that phase of reality with which he has gropingly and blunderingly tried to reckon in his various religions." Mordecai M. Kaplan, Judaism as a Civilization: Toward a Reconstruction of American-Jewish Life (Skokie: Varda Books, 2001), 315. And so while "There is only one universe within which both man and God exist. The so-called laws of nature represent the manner of God's immanent functioning. The element of creativity, which is not accounted for by the so-called laws of nature, and which points to the organic character of the universe or its life as a whole, gives us a clue to God's transcendent functioning. God is not an identifiable being who stands outside the universe. God is the life of the universe, immanent insofar as each part acts upon every other, and transcendent insofar as the whole acts upon each part" (ibid., 316). God is expressed within this universe but in his unity transcends it. So, for "those who cannot accept the orthodox view of religion [...] to find a place for the God-idea within the field of natural experience [...] They resolve the conflict between religion and science" by allowing religion reference "not to an aspect of reality which exists entirely outside the order identified as nature, but to an aspect of reality which is not taken into account in what is ordinarily called a naturalistic approach" (ibid., $316)$.

59 "I am not troubled in the least by the fact that God is not an identifiable being. For that matter neither is my Ego an identifiable being." (Kaplan, note, 15 January 1931, Communings, 431); "The thinking, representing, subject does not exist." (Wittgenstein, Tractatus, §5.631) "There really is just one world soul, which in particular I call my soul, and as which alone I grasp what I call the souls of others." (Wittgenstein, note 13 May 1915, Notebooks, 49).
} 
So for Kaplan religion is not a dualistic means of subsuming the material under the spiritual but a means of realising, or bringing-out, of the spiritual from the material. What we call the spiritual is not prior or superior to the physical, but is the elements of life which are most transcendent in their value, and only produced when we are set free from our base desires and animalistic drives. Religion for Kaplan provides a cohesive system of motivation which allows humanity to achieve their potential and better themselves and their world. By justifying the integrity of the individual, we create a freedom and responsibility which is impossible if the individual is understood as the sum of biological drives; and by integrating the community, we create a structure which promotes the benefit of all. This anti-reductionist picture is apparent in Wittgenstein when he continues to use the word "I" despite denying its existence, and reminds us that interpretation is far more important than facts alone.

\section{Conclusion}

Having examined the thought of Kaplan and Wittgenstein side by side, I have argued that there is a significant similarity in their accounts of a philosophy guided by the phenomenal actualities of human life and consciousness, in particular regard to how this should influence our understanding and practice of religion. While the strict immanence of meaning prompts a censure of traditional metaphysics most clearly for Wittgenstein (but also for Kaplan), I have shown that there is still a remnant of metaphysics found most clearly in Wittgenstein's conception of the transcendental self as still nothing but an aggregate of the material forms which constitute it - and this is one which correlates closely with Kaplan's depiction of God as fundamentally transcendent while yet existing wholly immanently in the material structure of the cosmos. Finally and crucially for both, it is only in the realm of human consciousness that the immanent can give way to the transcendent; and it is through this that meaning and truth can be found.

\section{BIBLIOGRAPHY}

\section{Primary Texts}

Kaplan, Mordecai M. The Meaning of God in Modern Jewish Religion. Detroit: Wayne State University Press, 1994. Originally published in 1937.

- The Future of the American Jew. New York: Macmillan, 1948.

Questions Jews Ask: Reconstructionist Answers. New York: The Reconstructionist Press, 1956.

- Judaism as a Civilization: Toward a Reconstruction of American-Jewish Life. Skokie: Varda Books, 2001. Originally published in 1981.

- Communings of the Spirit: The Journals of Mordecai M. Kaplan Volume I, 1913-1934. Edited by Mel Scult. Detroit: Wayne State University Press, 2001.

Wittgenstein, Ludwig. Tractatus Logico-Philosophicus. Translated by Pears \& McGuinness. London: Routledge, 1974. Originally published in 1922. 
Philosophical Investigations. Translated by G.E.M. Anscombe. New edition. Oxford: Blackwell, 1968. Originally published in 1953.

Remarks on the Foundations of Mathematics. Edited by G.H. von Wright, R. Rhees and G.E.M. Anscombe. Oxford: Basil Blackwell, 1956.

- Notebooks 1914-16. Edited by G.H. von Wright and G.E.M. Anscombe. Oxford: Blackwell, 1961.

"A Lecture on Ethics (1930)" Philosophical Review 74 (1965): 3-12.

- Lectures and Conversations on Aesthetics, Psychology, and Religious Belief. Edited by Cyril Barrett. Oxford: Basil Blackwell, 1967.

—. Zettel. Edited by G.E.M. Anscombe and G.H. von Wright. Translated by G.E.M. Anscombe. Oxford: Basil Blackwell, 1967.

—. On Certainty. Edited by G.E.M. Anscombe and G.H. von Wright. Translated by Denis Paul and G.E.M. Anscombe. Oxford: Basil Blackwell, 1975.

- Remarks on Frazer's Golden Bough. Translated by A.C. Miles and R. Rhees. Herefordshire: Brynmill, 1979.

- Culture and Value. Translated by Peter Winch. Chicago: University of Chicago Press, 1980.

- Remarks on the Philosophy of Psychology. Translated by G.E.M. Anscombe. Chicago: University of Chicago Press, 1980.

—. Philosophical Grammar. Edited by Rush Rhees. Translated by Anthony Kenny. Berkley: University of California Press, 2005.

\section{Secondary Texts.}

Breslauer, S. Daniel. Mordecai Kaplan's Thought in a Postmodern Age. Atlanta: Scholar's Press, 1994.

Chatterjee, Ranjit. Wittgenstein and Judaism: A Triumph of Concealment. New York: Peter Lang, 2005.

Clack, Brian R. Wittgenstein, Frazer and Religion. Basingstoke: Macmillan Press Ltd, 1999.

Husserl, Edmund. Ideas: General Introduction to Pure Phenomenology. Translated by W.R. Boyce Gibson. London: George Allen \& Unwin Ltd, 1931.

Keightley, Alan. Wittgenstein, Grammar and God. London: Epworth Press, 1976.

Kerr, Fergus. Theology After Wittgenstein. Oxford: Basil Blackwell, 1986.

Labron, Tim. Wittgenstein and Theology. London: T\&T Clark, 2009.

Langton, Daniel R. "Jewish Religious Thought, the Holocaust, and Darwinism: A Comparison of Hans Jonas and Mordecai Kaplan.” Aleph 13.2 (2013): 311-348.

Malcolm, Norman. Wittgenstein: A Religious Point of View? Edited by Peter Winch. New York: Cornell University Press, 1995.

McCutcheon, Felicity. Religion Within the Limits of Language Alone. London: Ashgate, 2001.

Scult, Mel. The Radical American Judaism of Mordecai M. Kaplan. Bloomington, IN: Indiana University Press: 2013.

Stokhof, Martin. World and Life as One. Ethics and Ontology in Wittgenstein's Early Thought. Palo Alto: Stanford University Press, 2002.

Willson, Mary F., and Christopher J. Whelan. "The Evolution of Fruit Color in FleshyFruited Plants.” The American Naturalist 136.6 (1990): 790-809. 